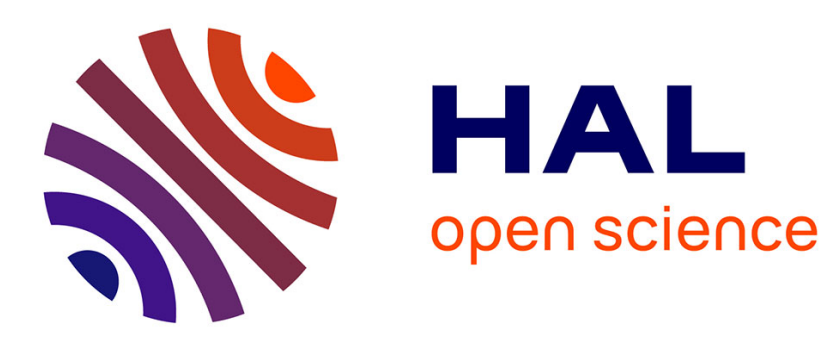

\title{
Design of Bifunctional Catalysts Based on Bea Zeolites for Tandem Processes with Participation of Ethanol
} N. O. Popovych, O. V. Larina, S. M. Orlyk, P. I. Kyriienko, S. O. Soloviev, S. Dzwigaj

\section{- To cite this version:}

N. O. Popovych, O. V. Larina, S. M. Orlyk, P. I. Kyriienko, S. O. Soloviev, et al.. Design of Bifunctional Catalysts Based on Bea Zeolites for Tandem Processes with Participation of Ethanol. Theoretical and Experimental Chemistry, 2018, 54 (4), pp.255 - 264. 10.1007/s11237-018-9571-9 . hal-01909683

\section{HAL Id: hal-01909683 \\ https://hal.sorbonne-universite.fr/hal-01909683}

Submitted on 31 Oct 2018

HAL is a multi-disciplinary open access archive for the deposit and dissemination of scientific research documents, whether they are published or not. The documents may come from teaching and research institutions in France or abroad, or from public or private research centers.
L'archive ouverte pluridisciplinaire HAL, est destinée au dépôt et à la diffusion de documents scientifiques de niveau recherche, publiés ou non, émanant des établissements d'enseignement et de recherche français ou étrangers, des laboratoires publics ou privés. 


\title{
DESIGN OF BIFUNCTIONAL CATALYSTS BASED ON BEA ZEOLITES FOR TANDEM PROCESSES WITH PARTICIPATION OF ETHANOL
}

\author{
N. O. Popovych, ${ }^{1}$ O. V. Larina, ${ }^{1}$ S. M. Orlyk, ${ }^{1}$ P. I. Kyriienko, ${ }^{1}$ \\ S. O. Soloviev, ${ }^{1}$ and S. Dzwigaj ${ }^{2}$
}

The results from the creation of BEA zeolite catalysts, containing heteroelements of $T a(\mathrm{Nb})$ and modified with $d$-metals ( $\mathrm{Ag}, \mathrm{Cu}, \mathrm{Zn}$ ), for processes involving ethanol, are presented. The activity of $\mathrm{Ag} / \mathrm{BEA}$ in the selective reduction of nitrogen oxides $\left(N O_{x}\right)$ with ethanol is due to the presence of acidic and surface redox sites; the promoting effect of hydrogen is produced by the presence of Lewis acid sites and silver nanoclusters. The highest ethanol conversion rates and selective formation of the target product with a high ( $>60 \%)$ yield in the production of 1,3-butadiene from ethanol are achieved in the presence of $\mathrm{Cu} / \mathrm{Ta} / \mathrm{SiBEA}$.

Key words: $\mathrm{BEA}$ zeolite; $\mathrm{SCR} \mathrm{NO}-\mathrm{C}_{2} \mathrm{H}_{5} \mathrm{OH}\left(+\mathrm{H}_{2}\right)$; $\mathrm{Ag} / \mathrm{BEA}$; Ta, $\mathrm{Nb}$ heteroelements; ethanol/acetaldehyde; 1,3-butadiene.

The creation of new and improvement of existing catalysts for complex (multistage) processes of both productive and ecological catalysis is based on the targeted construction of spatially organized structures with given functional characteristics $[1,2]$. The most effective catalysts for these processes are characterized by an optimum combination of functional sites on the surface. The realization of such so-called tandem processes requires the presence of various types of active sites [3] and of oxidation-reduction and acid-base sites in particular. For example, the most effective catalysts of $\mathrm{DeNO}_{x}$ processes (particularly the selective reduction of nitrogen oxides, a SCR process) are bifunctional and are characterized by a combination of oxidation-reduction and acid-base sites on the surface [4].

Zeolite catalysts are used in such processes because targeted control of their acid-base and redox characteristics is possible even at the synthesis step and particularly for zeolites with the BEA structure by dealumination followed by incorporation of the cations of certain heteroelements into the crystal lattice.

This work presents the results from the design of BEA zeolite catalysts based on determination of the role of the components of the catalytic compositions in revealing the bifunctional surface characteristics, the optimum combination of oxidation-reduction and acid-base sites for increased activity, selectivity, and productivity of the catalysts in processes involving ethanol - the selective reduction of nitrogen oxides (to molecular nitrogen) and the production of 1,3-butadiene.

\footnotetext{
${ }_{1}^{1}$ L. V. Pysarzhevsky Institute of Physical Chemistry, National Academy of Sciences of Ukraine, Nauky Ave., 31, Kyiv 03028, Ukraine. E-mail: orlyk@inphyschem-nas.kiev.ua.

${ }^{2}$ Sorbonne Universités, UPMC Univ Paris 06, CNRS, UMR 7197, Laboratoire de Réactivité de Surface, F-75005, Paris, France.
}

Translated from Teoreticheskaya i Éksperimental'naya Khimiya, Vol. 54, No. 4, pp. 235-243, July-August, 2018. 


\section{Ag/BEA ZEOLITES IN THE SELECTIVE CATALYTIC REDUCTION OF NO BY ETHANOL}

Compositions based on zeolites of various structural types (MFI, MOR, FAU, BEA) have been proposed for the selective catalytic reduction (SCR) of nitrogen oxides by organic compounds (hydrocarbons, oxygenates). Interest in silver-containing compositions increased significantly after discovery of the promoting effect of hydrogen on the $\mathrm{SCR}_{\mathrm{N}} \mathrm{NO}_{x}$ $[5,6]$. Considerable attention has been paid in the literature to investigation of the nature of the active sites of such catalysts, and $\mathrm{Ag}^{+}$ions [7-9], silver nanoclusters $\left(\mathrm{Ag}_{n}^{\delta+}, n \leq 8\right)$ [6], and surface structures of the $\mathrm{Ag}-\mathrm{O}-\mathrm{Al}$ type [10, 11] have been examined as active sites for the $\mathrm{SCR}$ of $\mathrm{NO}_{x}[7-9]$.

In order to determine the effect of aluminum in the composition of the Ag/BEA catalysts on the SCR of NO with ethanol zeolite catalysts with various degrees of dealumination, prepared by a two-step post-synthesis method, were investigated $[12,13]$. The preparation procedure included treatment with an aqueous solution of nitric acid at the first step in order to remove the organic template and aluminum atoms and impregnation of the zeolite with an aqueous solution of silver nitrate at the second step. Samples of zeolite catalysts with silicate modulus (Si/Al) of 12, 100, 200, and 1000 and silver content $1.5-4.0 \mathrm{wt} . \%$ were prepared.

The diffractograms of the initial AlBEA $(\mathrm{Si} / \mathrm{Al}=12)$, partly dealuminized AlSiBEA ( $\mathrm{Si} / \mathrm{Al}=100$ and 200$)$, and dealuminated $\mathrm{SiBEA}(\mathrm{Si} / \mathrm{Al}=1000)$ are typical of $\mathrm{BEA}$ zeolites and do not contain signs of amorphization or formation of new phases. The possibility of dealumination of BEA zeolite arises from the fact that in its structure already contains $\mathrm{T}$ atoms (i.e., vacancies of central aluminum atoms in the $\mathrm{TO}_{4}$ tetrahedra of which the zeolite matrix is composed), and the zeolite lattice is therefore "flexible," which makes it possible to remove $\mathrm{Al}$ atoms without loss of crystallinity [13, 14].

As a result of decrease in the volume of micropores $\left(237 \rightarrow 219 \mathrm{~cm}^{3} / \mathrm{g}\right)$ and increase in the volume of mesopores $\left(52 \rightarrow 55 \mathrm{~cm}^{3} / \mathrm{g}\right)$ treatment with nitric acid reduces the specific surface area of SiBEA and AlSiBEA somewhat in comparison with AlBEA $\left(625 \rightarrow 580 \mathrm{~m}^{2} / \mathrm{g}\right)$, as is demonstrated by low-temperature adsorption/desorption of nitrogen. With the introduction of silver the specific surface area and volume of the micropores decreases somewhat in line with its content $(4.0 \% \mathrm{Ag} / \mathrm{AlBEA}-$ $\left.605 \mathrm{~m}^{2} / \mathrm{g}, 233 \mathrm{~cm}^{3} / \mathrm{g} ; 3.0 \% \mathrm{Ag} / \mathrm{SiBEA}-567 \mathrm{~m}^{2} / \mathrm{g}, 210 \mathrm{~cm}^{3} / \mathrm{g}\right)$. The decrease of the volume of the mesopores $\left(52 \rightarrow 48 \mathrm{~cm}^{3} / \mathrm{g}\right.$ and $55 \rightarrow 49 \mathrm{~cm}^{3} / \mathrm{g}$ ) may indicate that nanoclusters of silver are formed in the zeolite cavities, thereby blocking access to the adsorbate [12].

Figure 1a shows the IR spectra of the investigated samples in the region of the stretching vibrations of the OH groups. The absorption bands in the spectrum of AlBEA belong to the hydroxyl groups attached to the aluminum ( 3781 and $\left.3667 \mathrm{~cm}^{-1}\right)$, acid $\mathrm{Al}-\mathrm{O}(\mathrm{H})-\mathrm{Si}\left(3615 \mathrm{~cm}^{-1}\right)$, and silanol $\mathrm{Si}-\mathrm{OH}\left(3750 \mathrm{~cm}^{-1}\right.$ with a shoulder at $\left.3740 \mathrm{~cm}^{-1}\right)$ groups [15]. After dealumination of the zeolite the absorption bands that belong to the $\mathrm{Al}-\mathrm{OH}$ and $\mathrm{Al}-\mathrm{O}(\mathrm{H})-\mathrm{Si}$ disappear, indicating removal of the aluminum from the lattice, and new bands appear $\left(3739,3709\right.$, and $\left.3529 \mathrm{~cm}^{-1}\right)$, corresponding respectively to the isolated inner, terminal inner, and $\mathrm{Si}-\mathrm{OH}$ groups with a hydrogen bond, located in the vacancies of the $\mathrm{T}$ atoms of the zeolite lattice [16]. For the partly dealuminated zeolites the intensity of the absorption bands of $\mathrm{Al}-\mathrm{OH}$ and $\mathrm{Al}-\mathrm{O}(\mathrm{H})-\mathrm{Si}$ is reduced, indicating incomplete removal of the aluminum from the zeolite lattice. The dealumination of the zeolites is also confirmed by the X-ray fluorescence method and ${ }^{27} \mathrm{Al}$ MAS-NMR [14]. With the introduction of Ag into the dealuminated (partly and fully) zeolites the intensity of the bands corresponding to the $\mathrm{OH}$ groups in the vacancies of the $\mathrm{T}$ atoms decreases, indicating that the silver is located at these positions.

In order to determine the valence state and dispersity of the silver the samples of the zeolite catalysts (after treatment under the conditions of SCR with ethanol in the presence of hydrogen) were studied by diffuse reflectance spectroscopy in the ultraviolet and visible spectral regions (DR UV-Vis spectroscopy) (Fig. 1b). The absorption bands at about $225 \mathrm{~nm}$ are due to electronic transitions in the $\mathrm{Ag}^{+}$cations, those at 260-290 nm are due to charge transfer in the nanoclusters $\operatorname{Ag}_{n}^{\delta+}(n \leq 8)$, while the absorption bands at $415 \mathrm{~nm}$ indicate the presence of metallic silver nanoparticles in the samples [5-7]. The intensity of the band at $225 \mathrm{~nm}$ is higher for the Ag/AlSiBEA(100) sample. With increase in the degree of dealumination the intensity of the bands corresponding to the silver nanoclusters decreases, and the intensity of the absorption bands of the silver nanoparticles increases. The presence of highly dispersed oxidized silver in the zeolites was confirmed by XPS on the basis of the proximity of the bond energies of the respective valence electrons. 

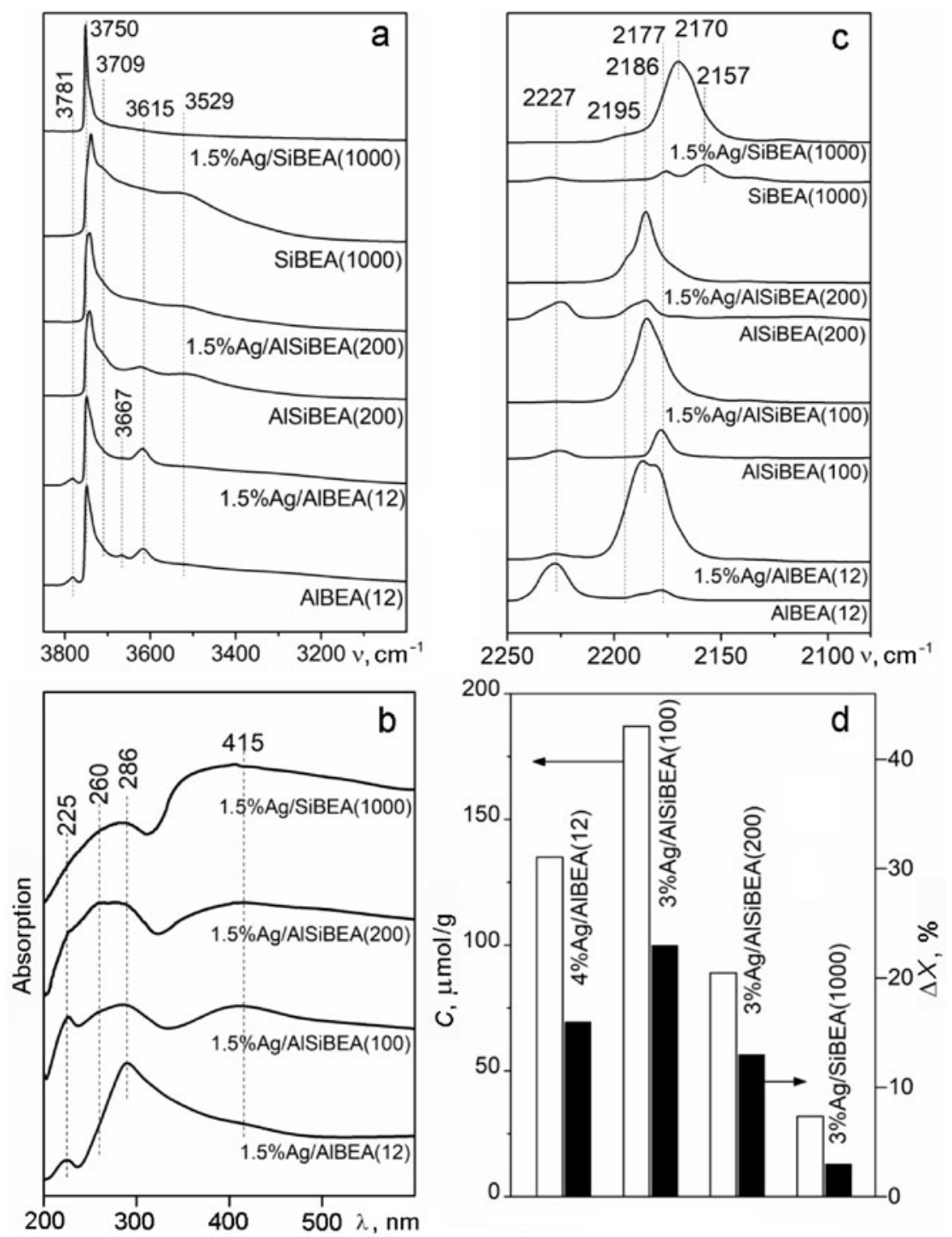

Fig. 1. Characteristics of Ag/AlSiBEA samples: IR spectra (a), UV spectra (b), IR spectra of $\mathrm{CO}$ adsorbed on the samples at $-173{ }^{\circ} \mathrm{C}$ and $10^{-3} \mathrm{~Pa}$ (c); the concentration of Lewis acid sites (IRS, pyridine, $150{ }^{\circ} \mathrm{C}$ ) and the increase of the conversion of $\mathrm{NO}(\Delta X, \%)$ during SCR with ethanol in the presence of $\mathrm{H}_{2}(\mathrm{~d})$.

For analysis of the electronic and coordination state of the active sites of the Ag/BEA zeolites samples with various degrees of dealumination were studied by the Fourier IR spectroscopy with low-temperature adsorption of CO (Fig. 1c). In the case of AlBEA and AlSiBEA the absorption band at $2177 \mathrm{~cm}^{-1}$ is characteristic of CO combined with the bridging hydroxyl groups of $\mathrm{Al}-\mathrm{O}(\mathrm{H})-\mathrm{Si}$ zeolite. The carbonyl band at $2227 \mathrm{~cm}^{-1}$ is characteristic of extra-framework aluminum. The main band in the IR spectrum of SiBEA $\left(2157 \mathrm{~cm}^{-1}\right)$ corresponds to CO combined with silanol groups $\mathrm{Si}-\mathrm{OH}$ in the vacancies of the T atom. As shown by the appearance of absorption bands at 2170-2195 $\mathrm{cm}^{-1}$, the introduction of silver into the BEA zeolites leads to the formation of new Lewis acid sites. The frequency of the stretching vibrations of $\mathrm{Ag}^{+}-\mathrm{CO}$ depends on the chemical composition of the support. Thus, the carbonyls on $\mathrm{Ag} / \mathrm{SiO}_{2}$ are characterized by $v(\mathrm{CO})$ at $2169 \mathrm{~cm}^{-1}$ [17], which is close to the value observed for $\mathrm{CO}$ adsorbed on the $\mathrm{Ag} / \mathrm{SiBEA}$ sample. The absorption band at $2186 \mathrm{~cm}^{-1}$ with a shoulder at about $2195 \mathrm{~cm}^{-1}$ in the spectra of Ag/AlBEA and Ag/AlSiBEA corresponds to the symmetrical and asymmetrical vibrations of the 
TABLE 1. Catalytic Activity of Ag-Containing BEA Zeolites in SCR of NO with Ethanol $(0.05 \% \mathrm{NO}+$ $0.1 \% \mathrm{C}_{2} \mathrm{H}_{5} \mathrm{OH}+10.0 \% \mathrm{O}_{2}\left(+0.5 \% \mathrm{H}_{2}\right)$ in $\left.\mathrm{He} ; 24000 \mathrm{~h}^{-1}\right)$

\begin{tabular}{l|c|c}
\hline \multirow{2}{*}{ Ag/BEA(Si/Al) catalyst } & \multicolumn{2}{|c}{ Conversion of $\mathrm{NO}, \%$ /attainment temperature, ${ }^{\circ} \mathrm{C}$} \\
\cline { 2 - 3 } & $\mathrm{NO}+\mathrm{C}_{2} \mathrm{H}_{5} \mathrm{OH}+\mathrm{O}_{2}$ & $\mathrm{NO}+\mathrm{C}_{2} \mathrm{H}_{5} \mathrm{OH}+\mathrm{O}_{2}+\mathrm{H}_{2}$ \\
\hline & & \\
$1.5 \% \mathrm{Ag} / \mathrm{AlBEA}(12)$ & $26 / 280-380$ & $32 / 280-370$ \\
$4.0 \% \mathrm{Ag} / \mathrm{AlBEA}(12)$ & $34 / 300-440$ & $50 / 350-385$ \\
$1.5 \% \mathrm{Ag} / \mathrm{AlSiBEA}(100)$ & $24 / 400-450$ & $48 / 390-420$ \\
$3.0 \% \mathrm{Ag} / \mathrm{AlSiBEA}(100)$ & $35 / 400-500$ & $57 / 400-435$ \\
$1.5 \% \mathrm{Ag} / \mathrm{AlSiBEA}(200)$ & $23 / 340-380$ & $27 / 355-400$ \\
$3.0 \% \mathrm{Ag} / \mathrm{AlSiBEA}(200)$ & $26 / 350-390$ & $39 / 365-410$ \\
$1.5 \% \mathrm{Ag} / \mathrm{SiBEA}(1000)$ & $27 / 310-350$ & $27 / 310-350$ \\
$3.0 \% \mathrm{Ag} / \mathrm{SiBEA}(1000)$ & $31 / 320-360$ & $34 / 310-335$ \\
\hline
\end{tabular}

$\mathrm{Ag}^{+}-(\mathrm{CO})_{2}$ dicarbonyls. This indicates at least two coordination vacancies for each $\mathrm{Ag}^{+}$cation, which exhibit the characteristics of Lewis acid sites (LAS).

In order to determine the amount and strength of the acid sites the zeolite samples were studied by IR spectroscopy with pyridine as probe molecule $[12,13]$. In the IR spectra of pyridine adsorbed on the Ag-containing zeolites there were new absorption bands at 1605 and $1450 \mathrm{~cm}^{-1}$, which correspond to Lewis acid sites. The intensity of these bands in the spectra of the $\mathrm{Ag} / \mathrm{AlBEA}$ samples increases with increase of the desorption temperature in comparison with the value in the spectra of the dealuminated (to various degrees) zeolites, which indicates an increase in the strength of the acid sites. The concentration of LAS was calculated from the integral intensities of the absorption bands at 1463,1455 , and $1450 \mathrm{~cm}^{-1}$ and the desorption temperature of the pyridine $150{ }^{\circ} \mathrm{C}$ (Fig. 1d). With increase of the $\mathrm{Si} / \mathrm{Al}$ ratio of the zeolite matrix from 12 to 100 the concentration of Lewis acid sites increases and then decreases with further increase of the ratio. Thus, the silver in the $\mathrm{Ag} / \mathrm{BEA}$ catalysts makes them bifunctional, forming both redox $\left(\mathrm{Ag}^{+}\right.$and $\left.\mathrm{Ag}_{n}^{\delta+}\right)$ and additional LAS.

Table 1 shows the values for the conversion of $\mathrm{NO}$ during selective reduction with ethanol and the temperature ranges in which they were reached. We note that the temperature dependences of NO conversion in the presence of $\mathrm{Ag} / \mathrm{BEA}$ zeolite catalysts are described by typical dome-shaped curves [13, 18]. A similar degree of transformation of NO was obtained for catalysts with different degrees of dealumination (100 and 200) and an identical Ag content at temperatures up to $350{ }^{\circ} \mathrm{C}$. At higher temperatures the conversion of $\mathrm{NO}$ on $\mathrm{Ag} / \mathrm{AlSiBEA}(200)$, unlike Ag/AlSiBEA(100), decreases. In the presence of samples with a smaller content of Brønsted and Lewis acid sites $(\mathrm{Ag} / \operatorname{SiBEA}(1000)$ and $\mathrm{Ag} / \mathrm{AlSiBEA}(200))$ the rate of oxidation of the ethanol by oxygen evidently increases with increase of temperature, and rate of reduction of $\mathrm{NO}_{x}$ decreases accordingly.

The role of the silver sites $\left(\mathrm{Ag}^{+}\right.$cations and $\mathrm{Ag}_{n}^{\delta+}$ clusters) involves activation of the alcohol adsorbed on the LAS containing silver by partial oxidation with the formation of more reactive intermediate products (enols) [18-20]. Over the strong Lewis acid sites on the surface of Ag/AlBEA the nitrate-nitrite adducts are stabilized over a wider range of temperatures and interact with reducing agent that is activated over the silver sites. For the dealuminated samples with a smaller content of LAS comparable rates of formation of the intermediates and their interaction are possible over a narrower range of temperatures.

The role of the LAS in the Ag/BEA zeolites was confirmed by investigating the catalysts by DRIFT spectroscopy in situ in a stream of $\mathrm{NO}+\mathrm{O}_{2}[18]$. Bands corresponding to bridged, bidentate, and monodentate nitrates were identified in the 
spectra of the $\mathrm{Ag} / \mathrm{AlBEA}(12)$ and $\mathrm{Ag} / \mathrm{SiBEA}(1000)$ samples, and their intensities were twice as high as those for the first sample. When the temperature was increased from 150 to $400{ }^{\circ} \mathrm{C}$ a decrease in the intensity of the bands was observed for both samples. At $400-500{ }^{\circ} \mathrm{C}$, however, the intensities of the bands for Ag/AlBEA(12) hardly change at all, in contrast to the significant decrease for $\mathrm{Ag} / \mathrm{SiBEA}(1000)$. Thus, the nitrate adducts over the strong Lewis acid sites of $\mathrm{Ag} / \mathrm{AlBEA}(12)$ are stabilized over a wider range of temperatures.

The effect of hydrogen on the selective reduction of NO in the presence of silver-containing BEA zeolites depends on the $\mathrm{Si} / \mathrm{Al}$ ratio of the samples. It should be noted that hydrogen is not a selective reducing agent for NO. (Reduction is not observed when there is no ethanol in the reaction mixture.) Figure $1 \mathrm{~d}$ shows the increases of the conversion of NO after addition of hydrogen for samples with various $\mathrm{Si} / \mathrm{Al}$ ratios. The addition of hydrogen to the reaction mixture $(0.05 \% \mathrm{NO}+$ $0.1 \% \mathrm{C}_{2} \mathrm{H}_{5} \mathrm{OH}+10.0 \% \mathrm{O}_{2}+0.5 \% \mathrm{H}_{2}$ in $\mathrm{He}$ ) increases the conversion of $\mathrm{NO}$ at $400{ }^{\circ} \mathrm{C}$ on the $\mathrm{Ag} / \mathrm{AlSiBEA}(100)$ samples: from $24 \%$ to $50 \%$ with a $1.5 \% \mathrm{Ag}$ content and from $35 \%$ to $56 \%$ in the case of $3.0 \% \mathrm{Ag}$. The effect of hydrogen is less significant in the presence of the catalysts based on $\operatorname{AlBEA}(12)$ and $\operatorname{AlSiBEA}(200)$ and is practically absent for $\mathrm{Ag} / \mathrm{SiBEA}(1000)$. The promoting effect of $\mathrm{H}_{2}$ is reversible; after removal of hydrogen from the gas mixture the conversion of NO is reduced to the value obtained in the absence of $\mathrm{H}_{2}$. The effect of $\mathrm{H}_{2}$ on the SCR process in the presence of Ag/BEA varies in line with the change in the content of Lewis acid sites in the zeolites.

In [21] it was shown that activation of $\mathrm{H}_{2}$ in the silver clusters deposited on $\theta-\mathrm{Al}_{2} \mathrm{O}_{3}(110)$ occurs in the region of contact between the cluster and the Lewis acid-base pair (Al-O). After dissociation of the hydrogen during interaction with the oxygen hydroxyl and hydroperoxide particles, which are more active in the partial oxidation of the reducing agent, are formed [22]. The insignificant promoting effect of $\mathrm{H}_{2}$ for the dealuminated $\mathrm{Ag} / \mathrm{SiBEA}$ zeolites may be due to the fact that the small surface concentration of the nitrate adducts levels out the increase in the rate of activation of the reducing agent in the presence of hydrogen. This is confirmed by the composition of the products from SCR of NO by ethanol $\left(+\mathrm{H}_{2}\right)$ : in the presence of $\mathrm{Ag} / \mathrm{SiBEA}(1000)$ the content of $\mathrm{CO}$ and acetaldehyde (the products of partial oxidation of the reducing agent) is increased after the addition of hydrogen to the reaction mixture, while the degree of transformation of the NO remains unchanged. A larger content of Lewis acid sites on the surface of Ag/AlSiBEA(100) leads to the appearance of a promoting effect from the hydrogen. It can therefore be supposed that the presence of the LAS on the surface of the catalyst is essential for the appearance of the $\mathrm{H}_{2}$ effect in the SCR of NO.

The role of the silver thus involves the formation of the oxidation-reduction and Lewis acid sites over which the reagents are activated. The wider temperature range for the SCR of NO by ethanol in the presence of Ag/AlBEA compared with the dealuminated (to various degrees) zeolites is due to the high concentration of strong Lewis acid sites, over which the nitrate adducts capable of interaction with the reducing agent activated over the silver-containing sites are stabilized. The promoting effect of the hydrogen on the selective reduction of the NO is ensured by the presence of Lewis acid sites and silver nanoclusters on the surface of the catalysts.

\section{MODIFICATION OF BEA ZEOLITES FOR THE PRODUCTION OF 1,3-BUTADIENE FROM ETHANOL}

Ethanol is a promising renewable feedstock for a series of valuable chemical products. One of them is 1,3-butadiene (BD), which is widely used in the production of polymeric materials [23]. It can be obtained from ethanol (the Lebedev method) and by conversion of a mixture of ethanol with acetaldehyde (AA) (the Ostromyslenskii method). Tantalum-silicate compositions $\mathrm{Ta}_{2} \mathrm{O}_{5}-\mathrm{SiO}_{2}$ are catalysts for the production of $\mathrm{BD}$ by conversion of a mixture of ethanol and AA [24, 25], in which the active sites are Lewis acid sites containing tantalum.

The use of BEA zeolite catalysts for the production of BD arises from the possibility of targeted control of their acid-base characteristics even at the synthesis step and in particular by dealumination followed by incorporation of certain heteroelements into the crystal lattice. The heteroelement can be present in the zeolite structure in two forms: built into the lattice (highly dispersed in the $\mathrm{M}^{n+}$ state) and outside the lattice (in the form of clusters and $\mathrm{MO}_{x}$ nanoparticles) [26]. In the zeolite materials with the incorporated heteroelements it is possible to achieve high selectivity in the production of BD on account of the formation of a large number of active sites in one of the key steps of the process - aldol condensation of the AA. 

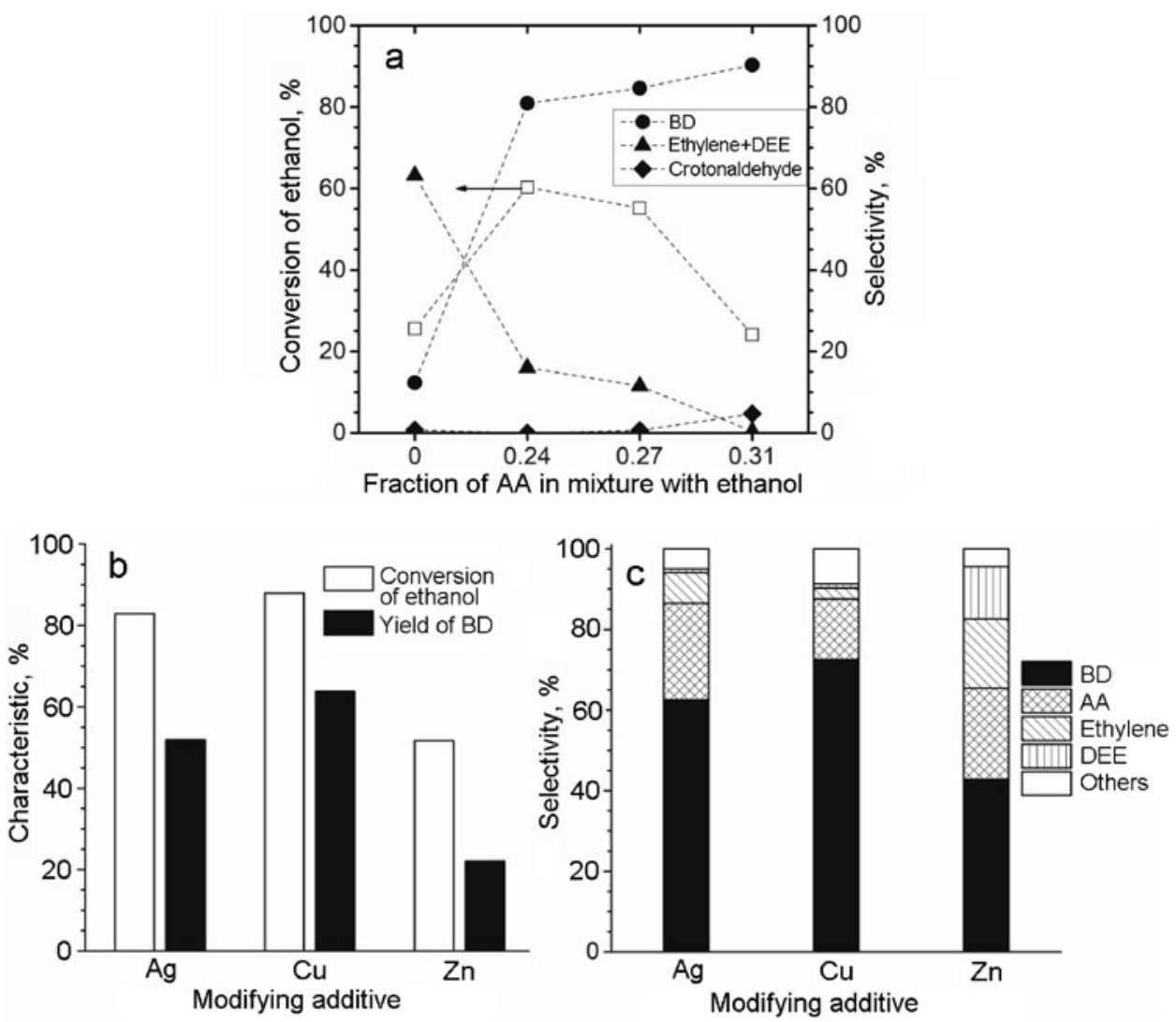

Fig. 2. Characteristics of the conversion of ethanol into 1,3-butadiene in the presence of zeolite compositions $3 \% \mathrm{Ta} / \mathrm{SiBEA} \quad$ (a) $\left(T=325{ }^{\circ} \mathrm{C}, \quad W=0.8 \mathrm{~h}^{-1}\right)$ and $1 \% \operatorname{Ag}(\mathrm{Cu}, \mathrm{Zn}) 1 \% \mathrm{Ta} / \mathrm{SiBEA}(\mathrm{b}, \mathrm{c})\left(T=325^{\circ} \mathrm{C}, W=0.5 \mathrm{~h}^{-1}\right)$.

The dealuminated BEA zeolites with incorporated tantalum atoms were prepared by a post-synthesis method [27, 28] and were characterized by XRD, IR spectroscopy, and DR UV-Vis spectroscopy. As a result of dealumination the Brønsted acid sites $[\mathrm{Al}-\mathrm{O}(\mathrm{H})-\mathrm{Si}]$, which are active in the side reactions of dehydration of ethanol to diethyl ether (DEE) and ethylene, are removed from the zeolite. Here, during subsequent incorporation of the heteroelement ( $\mathrm{Ta})$ Lewis acid $\left[\mathrm{Ta}^{+}(-\mathrm{O}-\mathrm{Si} \equiv)_{4}\right]$ and basic $\left[\mathrm{O}^{-} \mathrm{Ta}(-\mathrm{O}-\mathrm{Si} \equiv)_{4}\right]$ sites, which are active in the conversion of the ethanol/acetaldehyde mixture into 1,3-butadiene, are formed on the surface of the dehydrated Ta/SiBEA zeolite.

Samples of 1(3)\% Ta/SiBEA were studied in the conversion of ethanol and its mixture with AA. The zeolites are not very active in the conversion of ethanol, and the main products are AA, ethylene, and DEE. The selectivity in the formation of the targeted product is no higher than $16 \%$, and the yield of BD is low ( 3\%) (Fig. 2a). Increase of the tantalum content of the zeolite catalyst from 1 to $3 \mathrm{wt} . \%$ does not lead to any substantial increase in the yield of BD. At the same time, it is possible to achieve high selectivity in the conversion of the ethanol/AA mixture. The highest selectivity with respect to BD amounts to $87 \%-90 \%$ with $23 \%-28 \%$ conversion and AA fractional content of 0.31 in the mixture with ethanol, which is substantially higher than the values described in the literature [24].

The selectivity of formation of $\mathrm{BD}$ in the presence of Ta/SiBEA increases with increase of the AA content in the reaction mixture, and here the selectivity with respect to ethylene and DEE decreases. The amount of the products probably decreases on account of retardation of the side processes involving dehydration of the ethanol. The aldol condensation of AA and the dehydration of ethanol to ethylene and DEE occur over identical active sites (Lewis acid sites) and consequently compete. Since Meerwein-Ponndorf-Verley (MPV) reduction of crotonaldehyde (CA) also occurs over acid sites increase of the AA content of the initial reaction mixture can be expected to lead to a larger amount of CA in the reaction products. Crotyl 

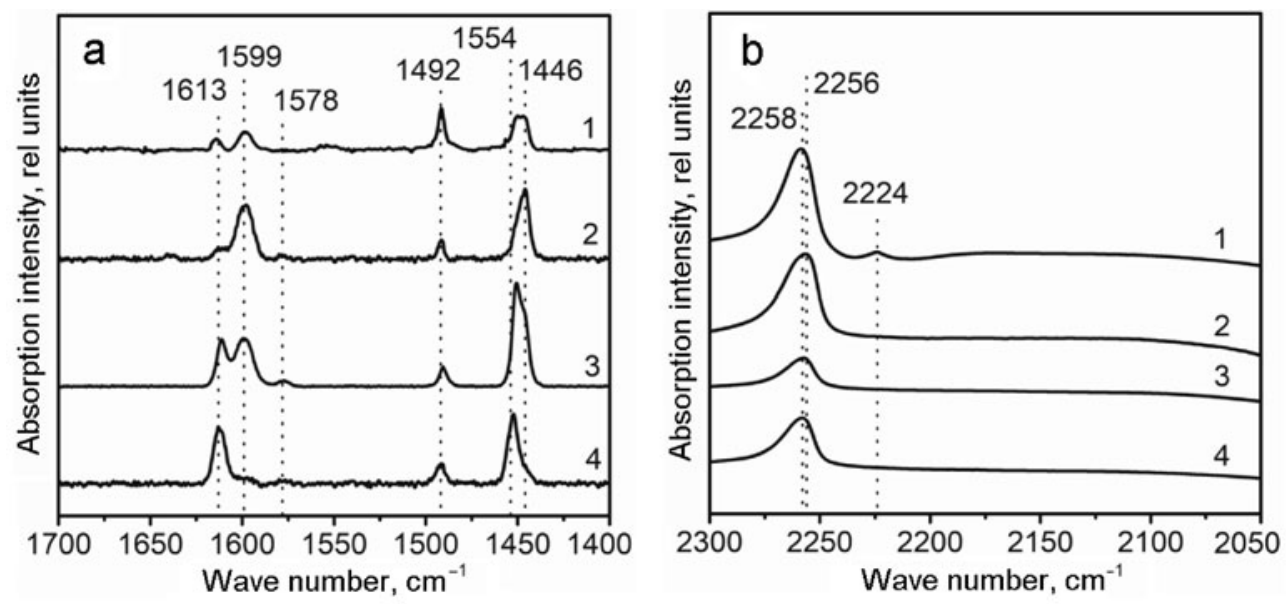

Fig. 3. IR spectra of adsorbed pyridine (a) and deuterochloroform (b) on samples $1 \% \quad \mathrm{Ta} / \mathrm{SiBEA} \quad(1), \quad 1 \% \quad \mathrm{Ag} / 1 \% \quad \mathrm{Ta} / \mathrm{SiBEA} \quad(2), \quad 1 \% \quad \mathrm{Cu} / 1 \% \quad \mathrm{Ta} / \mathrm{SiBEA} \quad(3)$, and $1 \% \mathrm{Zn} / 1 \% \mathrm{Ta} / \mathrm{SiBEA}(4)$ after vacuum treatment at $250{ }^{\circ} \mathrm{C}$ (pyridine) and $50{ }^{\circ} \mathrm{C}\left(\mathrm{CDCl}_{3}\right)$.

alcohol is not found in the products of conversion both of ethanol and of the ethanol/AA mixture, and it can therefore be stated that the targeted process is not limited by dehydration of the crotyl alcohol.

The high selectivity and the yield of the product (butadiene) are not changed after 7-8 $\mathrm{h}$ continuous use of the $\mathrm{Ta} / \mathrm{SiBEA}$ zeolite catalysts [29]. It should be noted that the crystal structure of the tantalum-containing catalysts is unchanged even after repeated cycles of use (total $\sim 400 \mathrm{~h}$ ) and subsequent regeneration (in a stream of $5 \% \mathrm{O}_{2}$ in $\mathrm{Ar}, 500{ }^{\circ} \mathrm{C}, 2 \mathrm{~h}$ ).

As mentioned above, the selectivity of formation of $\mathrm{BD}$ in the conversion of ethanol in the presence of the $\mathrm{Ta} / \mathrm{SiBEA}$ catalyst is less than $20 \%$, which is due to the insufficient reactivity of the active sites of the zeolite compositions for the key step of the process - the dehydrogenation of ethanol to AA. It is known that doping of oxide compositions with the compounds of $d$ metals and of silver, copper, and zinc in particular intensifies the dehydrogenation of ethanol [30-33].

To form surface active sites for dehydrogenation of ethanol to acetaldehyde the Ta/SiBEA zeolite catalyst was therefore doped with $d$ metals ( $\mathrm{Ag}, \mathrm{Cu}, \mathrm{Zn}$ ), and this led to a substantial increase of the conversion of ethanol and the selectivity with respect to BD (Fig. 2c, d). The highest values for these properties ( $88 \%$ and $73 \%$ respectively) were observed in the presence of $\mathrm{Cu} / \mathrm{Ta} / \mathrm{SiBEA}$ zeolite. The selectivity of formation of $\mathrm{BD}$ at $\mathrm{Ag} / \mathrm{Ta} / \mathrm{SiBEA}$ was also fairly high $(63 \%$ at $83 \%$ conversion of ethanol). In the presence of the $\mathrm{Zn} / \mathrm{Ta} / \mathrm{SiBEA}$ sample the selectivity for $\mathrm{BD}$ amounts to $43 \%$ at $52 \%$ conversion of ethanol. Here significant amounts of AA (selectivity of $23 \%$ ), ethylene, and DEE (overall selectivity of 30\%) are observed in the reaction products, indicating an insufficient amount of acid sites of medium strength for the aldol condensation and a significant amount of strong-acid sites that are active in the ethanol dehydrogenation side reactions.

Increase of the load on the $\mathrm{Cu} / \mathrm{Ta} / \mathrm{SiBEA}$ catalyst (ethanol weight hourly space velocity increased by three times - to $1.5 \mathrm{~h}^{-1}$ ) leads to a substantial decrease in the conversion of ethanol, the selectivity of formation of the targeted product, and the productivity of the catalyst with respect to $\mathrm{BD}-$ from 0.19 to $0.12 \mathrm{~g} /\left(\mathrm{g}_{\text {cat }} \cdot \mathrm{h}\right)$ [34]. Here the amount of dehydration products (ethylene and DEE) and acetaldehyde in the reaction products is increased significantly due to the kinetics of the multistage process.

In order to determine the role of the additions of $d$ metals $(\mathrm{Ag}, \mathrm{Cu}, \mathrm{Zn})$ in the formation of the active sites of the $\mathrm{Ta} / \mathrm{SiBEA}$ zeolites the modified samples were investigated by IR spectroscopy with the use of probe molecules (pyridine and deuterochloroform, $\mathrm{CDCl}_{3}$ ).

The IR spectra of pyridine adsorbed on the surface of the modified Ta/SiBEA samples contain bands that indicate the presence of Lewis acid sites (absorption bands at 1613, 1599, 1492, 1454, and $1446 \mathrm{~cm}^{-1}$ ) (Fig. 3a) [14, 35-37]. The absorption bands of pyridine coordinatively bound to the Lewis acid sites are significantly weaker for Ta/SiBEA. It can therefore be assumed that additional acid sites are formed in the matrix of the dealuminated BEA zeolite on account of entry of the silver, copper, or zinc ions into the vacancies of the $\mathrm{T}$ atoms. On the basis of the intensities of the bands in the IR spectra of the 
TABLE 2. Catalytic Characteristics of $\mathrm{Nb} / \mathrm{SiBEA}$ Zeolite Catalysts in the Conversion of Ethanol and the Ethanol/Acetaldehyde Mixture $\left(T=325^{\circ} \mathrm{C}, W=0.8 \mathrm{~h}^{-1}\right)$

\begin{tabular}{|c|c|c|c|c|c|c|c|c|c|c|}
\hline \multirow{3}{*}{ Catalyst } & \multirow{3}{*}{$\begin{array}{c}\text { Conversion, } \\
\%\end{array}$} & \multicolumn{6}{|c|}{ Selectivity, \% } & \multicolumn{3}{|c|}{ Specific rate, $\mathrm{mol} /(\mathrm{mol} \mathrm{Nb} \cdot \mathrm{h})$} \\
\hline & & \multirow[b]{2}{*}{$\mathrm{BD}$} & \multirow[b]{2}{*}{ AA } & \multirow[b]{2}{*}{ Ethylene } & \multirow[b]{2}{*}{ DEE } & \multirow[b]{2}{*}{$\mathrm{CA}$} & \multirow[b]{2}{*}{ Others } & \multirow{2}{*}{$\begin{array}{c}\text { Transformations } \\
\text { of ethanol } \\
\text { (ethanol/AA) }\end{array}$} & \multicolumn{2}{|c|}{ Formation of } \\
\hline & & & & & & & & & $\mathrm{BD}$ & $\begin{array}{c}\text { Ethylene + } \\
\text { DEE }\end{array}$ \\
\hline \multicolumn{11}{|c|}{ Ethanol } \\
\hline $0.7 \% \mathrm{Nb} / \mathrm{SiBEA}$ & 42.4 & 27.9 & 16.8 & 42.0 & 12.2 & 0.1 & 1.0 & 98 & 27 & 53 \\
\hline $2 \% \mathrm{Nb} / \mathrm{SiBEA}$ & 27.1 & 26.0 & 29.6 & 28.0 & 15.6 & 0.1 & 0.7 & 22 & 6 & 10 \\
\hline \multicolumn{11}{|c|}{ Ethanol/AA $=2.7$} \\
\hline $0.7 \% \mathrm{Nb} / \mathrm{SiBEA}$ & 38.5 & 54.8 & - & 36.8 & 2.4 & 2.5 & 3.5 & 89 & 49 & 35 \\
\hline $2 \% \mathrm{Nb} / \mathrm{SiBEA}$ & 22.1 & 70.6 & - & 11.9 & 2.0 & 11.8 & 3.7 & 18 & 13 & 3 \\
\hline
\end{tabular}

modified ( $\mathrm{Ag}, \mathrm{Cu}, \mathrm{Zn}) \mathrm{Ta} / \mathrm{SiBEA}$ zeolites after desorption of the pyridine at $350^{\circ} \mathrm{C}$ a larger amount of strong Lewis acid sites is observed for the zinc-containing sample. Weak LAS are mostly present in the $\mathrm{Ag} / \mathrm{Ta} / \mathrm{SiBEA}$ zeolite.

In the IR spectrum of deuterochloroform adsorbed on the surface of the Ta/SiBEA sample there are bands at 2558 and $2556 \mathrm{~cm}^{-1}$, which indicate the presence of weak basic sites (Fig. 3b) [38]. In the IR spectra of the modified samples the intensity of these bands is significantly lower. Moreover, the absorption band of $\mathrm{CDCl}_{3}$ adsorbed on the basic sites of medium strength $\left(\sim 2220 \mathrm{~cm}^{-1}\right)$ is absent from the spectra, indicating that the introduction of silver, copper, or zinc into the composition of $\mathrm{Ta} / \mathrm{SiBEA}$ leads to blockage of the basic sites of medium strength with a simultaneous decrease in the amount of weak sites.

Comparison of the results of IR spectroscopy of the modified zeolites with the characteristics of the targeted process of production of BD from ethanol in their presence indicates that the incorporation of silver, copper, and zinc into the Ta/SiBEA zeolite leads to the formation of additional LAS that are active in the aldol condensation of AA. Here a large concentration of strong Lewis acid sites, which accelerate the side reaction of dehydration of ethanol to ethylene, is observed for the copper- and zinc-containing samples. With the addition of silver predominantly weak Lewis acid sites, less active in the targeted process, are formed.

According to the results from DR UV-Vis spectroscopy, XPS, and TEM methods there are clusters and subnanoparticles of the metals $(\mathrm{Ag}, \mathrm{Cu}, \mathrm{Zn}$ ) on the surface of the modified Ta/SiBEA compositions. Their stabilization in a highly dispersed state even after catalysis is promoted by the silicate matrix of the zeolite. Their role mainly includes the formation of active sites for dehydrogenation of ethanol to AA at a higher rate than over the basic sites of Ta/SiBEA. It can be supposed that the dehydrogenation of ethanol occurs over active sites formed with the participation of silver, copper, and zinc, while further transformation of the ethanol/AA mixture by aldol condensation, MPV reduction, and dehydration of the formed CA take place over the tantalum-containing acid sites of the zeolite. The production of BD from ethanol in the presence of $\mathrm{M} / \mathrm{Ta} / \mathrm{SiBEA}(\mathrm{M}: \mathrm{Ag}, \mathrm{Cu}, \mathrm{Zn}$ ) can be represented schematically in the following way:

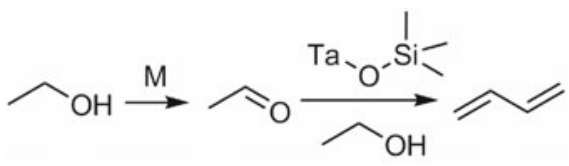

The effect of the nature of the niobium particles in the $\mathrm{Nb} / \mathrm{SiBEA}$ zeolites on their catalytic characteristics in tandem processes and in the production of 1,3-butadiene from ethanol in particular was established in [26]. 
It was shown that the active sites formed with the participation of the various states of niobium in the structure of the $\mathrm{Nb} / \mathrm{SiBEA}$ zeolite accelerate various steps of the production of BD from ethanol. Incorporation of the niobium into the crystal lattice of dealuminated BEA zeolite at the vacancies of the T atoms is confirmed by XRD, NMR, IR and DR UV-Vis spectroscopy; the ratio of niobium in the various states depends on its $(\mathrm{Nb})$ amount added to the sample. According to the results from DR UV-Vis spectroscopy the $\mathrm{Nb} / \mathrm{SiBEA}$ samples $(0.7$ and $2 \mathrm{wt} . \% \mathrm{Nb})$ contain highly dispersed niobium in the $\mathrm{Nb}^{5+}$ state; the first sample contains a larger amount of incorporated $\mathrm{Nb}(\mathrm{V})$, whereas the second sample contains extra-framework $\mathrm{Nb}(\mathrm{V})$ and $\mathrm{NbO}_{x}$ nanoparticles.

Table 2 gives data on the catalytic activity (selectivity) of the $\mathrm{Nb} / \mathrm{SiBEA}$ zeolites in the conversion of ethanol and its mixture with AA. The main products from the conversion of ethanol are BD, AA, ethylene, and DEE, and small amounts $(<1 \%)$ of crotonaldehyde and butene isomers were also detected. The $0.7 \% \mathrm{Nb} / \mathrm{SiBEA}$ catalyst is characterized by a high ethanol conversion rate and selectivity for the formation of $\mathrm{BD}$, as a result of which the yield of $\mathrm{BD}$ is almost twice the yield for the $2.0 \% \mathrm{Nb} / \mathrm{SiBEA}$ sample. The samples also differ with respect to the dehydrogenation (AA) and dehydration (ethylene and $\mathrm{DEE}$ ) products. The higher selectivity for the formation of AA on $2.0 \% \mathrm{Nb} / \mathrm{SiBEA}$ is probably due to the smaller number of aldol condensation sites on its surface for subsequent transformation of AA to BD. The higher selectivity of the $0.7 \% \mathrm{Nb} / \mathrm{SiBEA}$ sample for ethylene and DEE indicates a larger number of acid sites over which the ethanol dehydration side reaction occurs.

The transformation of the ethanol/AA mixture gives a higher degree of conversion and a higher yield of the targeted product (BD) in the presence of $0.7 \% \mathrm{Nb} / \mathrm{SiBEA}$. On this basis it can be supposed that the aldol condensation takes place with a higher rate over the sites formed with participation of the $\mathrm{Nb}(\mathrm{V})$ incorporated into the crystal lattice of the BEA. At the same time, substantially higher selectivity for the formation of $\mathrm{BD}(70.6 \%)$ is obtained on the $2.0 \% \mathrm{Nb} / \mathrm{SiBEA}$ catalyst than on $0.7 \% \mathrm{Nb} / \mathrm{SiBEA}(54.8 \%)$.

The observed increase of the amount of ethylene (from $11.9 \%$ to $29.5 \%$ ) in the products of conversion of the ethanol/AA mixture in the presence of the $2.0 \% \mathrm{Nb} / \mathrm{SiBEA}$ catalyst and the almost identical value of the selectivity for the formation of $\mathrm{BD}$ for the sample with $0.7 \%$ of $\mathrm{Nb}$ with increase of the temperature of the process from 325 to $350{ }^{\circ} \mathrm{C}$ give reason to suppose that the ethanol dehydration side reaction can occur over acid sites formed by extra-framework $\mathrm{Nb}(\mathrm{V})$ and $\mathrm{NbO}_{x}$.

The products of transformation of the mixture of ethanol with AA in the presence of $2.0 \% \mathrm{Nb} / \mathrm{SiBEA}$ contain a significantly larger amount of CA (10.5\%-11.8\%). The considerable difference in the selectivity of formation of CA may be due to the fact that its reduction by ethanol becomes a key factor in the production of BD.

To assess the effect of the location of the niobium in the BEA zeolite matrix on the activity of the $\mathrm{Nb} / \mathrm{SiBEA}$ samples in the MPV reduction of CA by ethanol their activity in the transformation of the ethanol/CA mixture was tested [26]. A higher degree of conversion and a larger amount of BD produced (58.2\%) were observed on the $0.7 \% \mathrm{Nb} / \mathrm{SiBEA}$ sample, and it can therefore be assumed that the MPV reduction takes place at a higher rate over the sites formed with participation of incorporated $\mathrm{Nb}(\mathrm{V})$.

The specific rate of formation of 1,3-butadiene (turnover frequency (TOF)) in the transformation processes of ethanol and ethanol/AA mixture over the $0.7 \% \mathrm{Nb} / \mathrm{SiBEA}$ catalyst, which only contains $\mathrm{Nb}(\mathrm{V})$ incorporated into the crystal lattice of BEA zeolite, is several times higher than the TOF for the $2.0 \% \mathrm{Nb} / \mathrm{SiBEA}$ sample with extra-framework $\mathrm{Nb}(\mathrm{V})$ and nanodispersed $\mathrm{NbO}_{x}$ (Table 2). The rate of dehydrogenation of ethanol in the presence of $0.7 \% \mathrm{Nb} / \mathrm{SiBEA}$ is almost four times higher than for $2.0 \% \mathrm{Nb} / \mathrm{SiBEA}$. The $0.7 \% \mathrm{Nb} / \mathrm{SiBEA}$ sample is also more active in the side reactions of dehydration of ethanol to ethylene and DEE, which take place over the acid sites on the surface of the catalyst.

Thus, the dehydrogenation of ethanol, the aldol condensation of AA, and its MPV reduction by ethanol, and likewise the tandem process for the production of BD from ethanol, take place more effectively over the Lewis acid sites formed by $\mathrm{Nb}(\mathrm{V})$ incorporated into the BEA zeolite matrix than over the sites formed with participation of extra-framework $\mathrm{Nb}(\mathrm{V})$ and $\mathrm{NbO}_{x}$ nanoparticles.

To summarize the results of the investigations into the bifunctional nature of the active sites on the surface of zeolite catalysts with the BEA structure we draw attention to the following points. The appearance of SCR activity in Ag/BEA catalysts and the promoting effect of hydrogen on the selective reduction of nitrogen oxides $\left(\mathrm{NO}_{x}\right)$ by ethanol arises from the bifunctional surface characteristics, i.e., the presence of acid sites and redox sites. Effective catalysts for the production of 1,3-butadiene from ethanol are proposed as a result of investigation of the nature of the effect of the active components and modifying additives of $\mathrm{Cu}(\mathrm{Ag}, \mathrm{Zn}) / \mathrm{Ta} / \mathrm{SiBEA}$ zeolite compositions on the acid-base characteristics of the surface; the highest 
degrees of conversion and selectivity for the formation of the targeted product (butadiene) with high yields $(>60 \%)$ are obtained in the presence of $\mathrm{Cu} / \mathrm{Ta} / \mathrm{SiBEA}$. Incorporation of niobium into the structure of the BEA zeolite leads to the formation of a larger amount of Lewis acid sites per mole of $\mathrm{Nb}$. This makes it possible to produce $\mathrm{BD}$ from ethanol (ethanol/acetaldehyde mixture) in the presence of catalysts with smallest content of active component.

\section{REFERENCES}

1. A. Corma, Angew. Chem. Int. Ed., 55, 6112-6113 (2016).

2. C. M. Friend and B. Xu, Account. Chem. Res., 50, 517-521 (2017).

3. M. J. Climent, A. Corma, S. Iborra, and M. J. Sabater, ACS Catal., 4, 870-891 (2014).

4. N. O. Popovych, S. O. Soloviev, and S. M. Orlyk, Teor. Éksp. Khim., 52, No. 3, 133-151 (2016). [Theor. Exp. Chem., 52, No. 3, 133-151 (English translation).]

5. J. Shibata, K. I. Shimizu, Y. Takada, et al., J. Catal., 227, 367-374 (2004).

6. J. Shibata, Y. Takada, A. Shichi, et al., J. Catal., 222, 368-376 (2004).

7. N. Bogdanchikova, F. C. Meunier, M. Avalos-Borja, et al., Appl. Catal. B, 36, 287-297 (2002).

8. K.-I. Shimizu, J. Shibata, H. Yoshida, et al., Appl. Catal. B, 30, 151-162 (2001).

9. A. Iglesias-Juez, M. Fernández-García, A. Martínez-Arias, et al., Top. Catal., 30/31, 65-70 (2004).

10. X. She and M. Flytzani-Stephanopoulos, J. Catal., 237, 79-93 (2006).

11. H. Deng, Y. Yu, F. Liu, et al., ACS Catal., 4, 2776-2784 (2014).

12. S. Dzwigaj, N. O. Popovych, P. I. Kyriienko, et al., Micropor. Mesopor. Mater., 182, 16-24 (2013).

13. N. O. Popovych, P. I. Kyriienko, S. O. Soloviev, et al., Micropor. Mesopor. Mater., 226, 10-18 (2016).

14. S. Dzwigaj, Y. Millot, J.-M. Krafft, et al., J. Phys. Chem. C, 117, 12552-12559 (2013).

15. K. Chakarova and K. Hadjiivanov, J. Phys. Chem. C, 115, $4806-4817$ (2011).

16. K. I. Hadjiivanov and G. N. Vayssilov, Adv. Catal.-Elsevier Inc., 307-511 (2002).

17. K. Hadjiivanov and H. Knözinger, J. Phys. Chem. B, 102, 10936-10940 (1998).

18. N. O. Popovych, P. I. Kyriienko, S. O. Soloviev, et al., Micropor. Mesopor. Mater., 203, 163-169 (2015).

19. Y. Yan, Y. Yu, H. He, and J. Zhao, J. Catal., 293, 13-26 (2012).

20. H. He, Y. Li, X. Zhang, et al., Appl. Catal. A., 375, 258-264 (2010).

21. P. Hirunsit, K. Shimizu, R. Fukuda, et al., J. Phys. Chem. C, 118, 7996-8006 (2014).

22. K. Sawabe, T. Hiro, K. I. Shimizu, and A. Satsuma, Catal. Today, 153, 90-94 (2010).

23. G. Pomalaza, M. Capron, V. Ordomsky, and F. Dumeignil, Catalysts, 6, 203-238 (2016).

24. H.-J. Chae, T.-W. Kim, Y.-K. Moon, et al., Appl. Catal. B, 150/151, 596-604 (2014).

25. T.-W. Kim, J.-W. Kim, S.-Y. Kim, et al., Chem. Eng. J., 278, 217-223 (2015).

26. P. I. Kyriienko, O. V. Larina, N. O. Popovych, et al., J. Mol. Catal. A, 424, $27-36$ (2016).

27. S. Dzwigaj, Y. Millot, and M. Che, Catal. Lett., 135, 169-174 (2010).

28. F. Tielens, T. Shishido, and S. Dzwigaj, J. Phys. Chem. C, 114, $9923-9930$ (2010).

29. P. I. Kyriienko, O. V. Larina, S. O. Soloviev, et al., Catal. Commun., 77, 123-126 (2016).

30. W. Janssens, E. V. Makshina, P. Vanelderen, et al., ChemSusChem, 8, 994-1008 (2015).

31. C. Angelici, M. E. Z. Velthoen, B. M. Weckhuysen, and P. C. A. Bruijnincx, ChemSusChem, 7, 2505-2515 (2014).

32. Y. Sekiguchi, S. Akiyama, W. Urakawa, et al., Catal. Commun., 68, 20-24 (2015).

33. T. Yan, W. Dai, G. Wu, et al., ACS Catal., 8, 2760-2773 (2018).

34. P. I. Kyriienko, O. V. Larina, S. O. Soloviev, et al., ACS Sustain. Chem. Eng., 5, 2075-2083 (2017).

35. A. Corma, F. X. Llabrés I Xamena, C. Prestipino, et al., J. Phys. Chem. C, 113, 11306-11315 (2009).

36. S. Dzwigaj, J. Janas, J. Gurgul, et al., Appl. Catal. B, 85, 131-138 (2009).

37. V. S. Marakatti and A. B. Halgeri, RSC Adv., 5, 14286-14293 (2015).

38. C. Angelici, M. E. Z. Velthoen, B. M. Weckhuysen, and P. C. A. Bruijnincx, Catal. Sci. Technol., 5, 2869-2879 (2015). 